\title{
Measles inclusion-body encephalitis in a child with treated acute lymphoblastic leukaemia
}

\author{
H. C. DRYSDALE, LILIAN F. JONES, D. R. OPPENHEIMER, AND \\ A. H. TOMLINSON
}

From the Departments of Haematology and Paediatrics, Princess Margaret Hospital, Swindon, and the Department of Neuropathology and Public Health Laboratory, Radcliffe Infirmary, Oxford

SYNOPSIS A child with acute lymphoblastic leukaemia, being treated in the UKALL II Trial, had while in remission an attack of measles and made a normal recovery. Four months later she developed an acute encephalopathy and died within two weeks. The brain showed mild inflammatory features and widespread inclusion bodies in neurones and glial cells. Immunofluorescence proved an infection with measles virus. Similar cases have been called SSPE; reasons are given for preferring the term 'measles inclusion-body encephalitis'.

Patients whose immune responses are depressed by disease, by cytotoxic drugs, or by radiotherapy are notoriously susceptible to unusual types of infection by viruses, especially those of the herpes group. We report an encephalitis which occurred four months after an attack of measles in a child with acute lymphoblastic leukaemia (ALL), under treatment and in remission.

\section{Clinical history}

Birth was premature at 30 weeks' gestation (birthweight $1.6 \mathrm{~kg}$ ) and was followed by severe jaundice requiring exchange transfusion. Early progress was slightly retarded, but later mental and physical development was considered normal. The child was said to have had measles, German measles, and chicken-pox during infancy but had been otherwise well. She had received triple vaccine immunization.

In June 1973, at the age of 45 months she was admitted to the RAF Hospital, Wroughton for investigation of a painful ankle. Peripheral blood and bone marrow examination resulted in the diagnosis of ALL. She was transferred to the Princess Margaret Hospital, Swindon where she was entered on the UKALL II Trial. She received standard induction therapy with a single transfusion of stored blood and went smoothly into remission. Details of her subsequent treatment and course are shown in figure 1. It will be seen that treatment was interruped on several occasions, either because of severe depression of haematological values or because of Received for publication 17 March 1976 various intercurrent infections. In November 1973 at the time of a measles epidemic, she developed a fever, typical rash, conjuctivitis, and vomiting and was diagnosed by one of us (LFJ) as having measles. The mother's statement that she had had measles in infancy lacked confirmation. The rash subsided normally.

The final course of methotrexate in early April 1974 was well tolerated, but three days later the child became drowsy, mentally confused, and unsteady with intermittent headaches. On admission to hospital there were no focal neurological signs and no evidence of meningeal irritation. The fundi were normal. The cerebrospinal fluid (CSF) was under normal pressure and contained no cells; protein and glucose contents were normal. Haematological values returned swiftly to normal with cessation of therapy, and the bone marrow showed complete remission. Electrolytes, urea, sugar, and liver function tests were normal. Candida was grown from a throat swab, and Escherichia coli from the urine, but blood culture was negative.

She became more drowsy and withdrawn and was eventually unresponsive to verbal or visual stimuli. An electroencephalogram was reported as showing generalized abnormalities with some focal discharges on the right side. She developed generalized and focal epileptic seizures, which persisted despite anticonvulsant therapy and dexamethasone. CSF examination again showed no abnormality. The child became unconscious, showed signs of a chest infection, and died aged 55 months, two weeks after the onset of the cerebral disorder. 


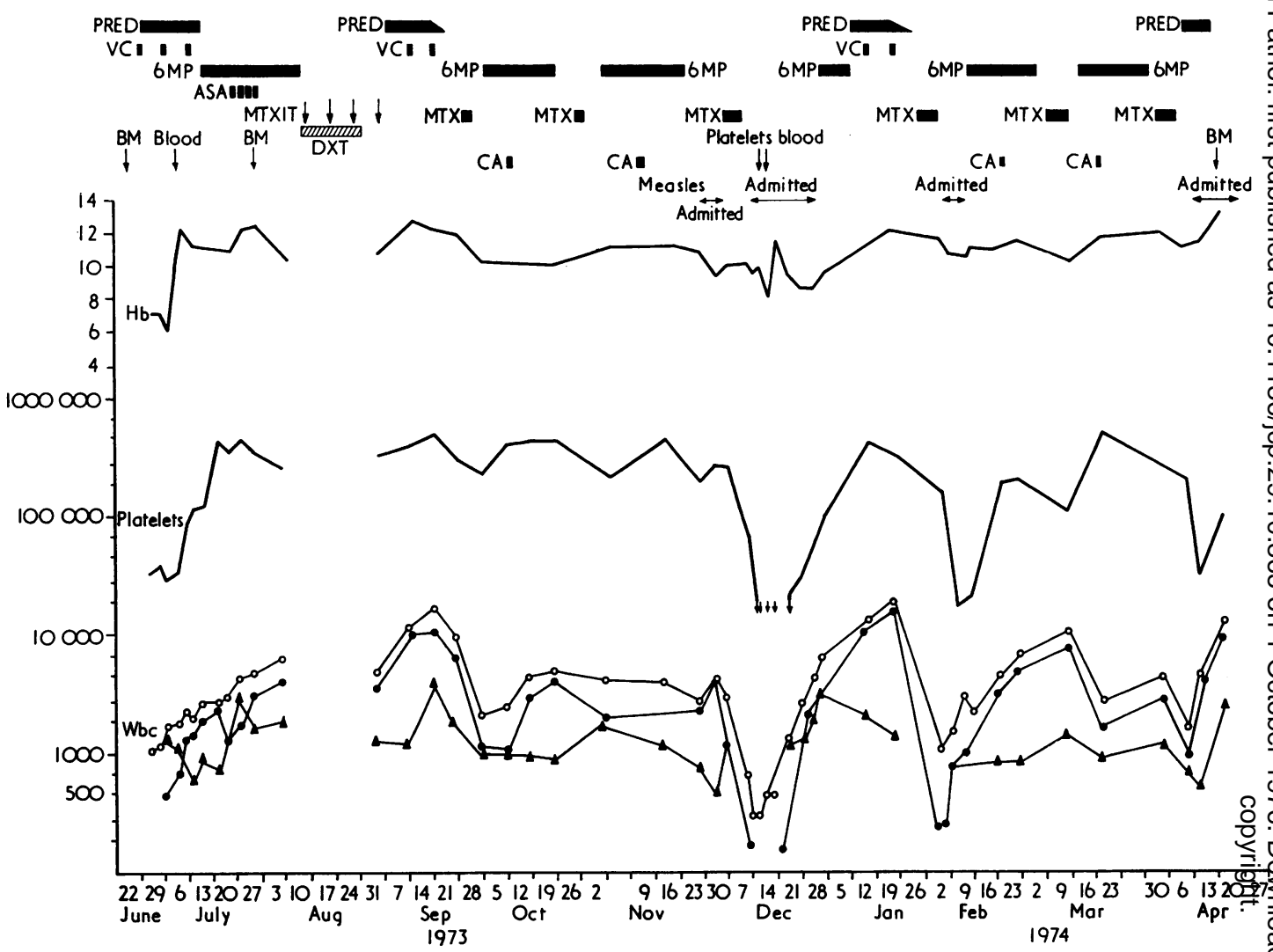

Fig 1 Chart showing treatment, clinical course, and haematological values over a 10-month period. Pred = prednisolone; $V C=$ vincristine; $6 M P=6$-mercaptopurine; $A S A=$ asparaginase; $M T X=$ methotrexate; $I T=$ intrathecal $; D X T=$ deep $\mathrm{x}$-ray therapy; $C A=$ cytosine arabinoside; $B M=$ bone marrow.

\section{Necropsy findings}

There was consolidation of the lower lobes of both lungs, a small acute ulcer in the second part of the duodenum, and a tiny stone in the pelvis of the right kidney. Apart from the brain, all other organs appeared to be normal.

On microscopy the nodes showed only reactive hyperplasia. There was severe acute-on-chronic bronchopneumonia without giant cells, and some round-cell infiltration and marked mitotic activity in lymphoid aggregations adjacent to bronchi. It was difficult to be certain whether this represented a residual leukaemic focus, but, in view of the considerable infective stimulus, it was thought to be more probably reactive in nature. No other foci suggestive of residual leukaemia were found.

\section{PATHOLOGY OF THE BRAIN}

Without the ventricular fluid the whole brain weighed
$1100 \mathrm{~g}$. The brainstem and cerebellum weighed $140 \mathrm{~g}$ The cerebral convolutions were of normal pattero and were not flattened. When sliced, there was gross symmetrical dilatation of the lateral and third. ventricles which appeared to be at the expense of white matter (fig 2). Cortex and central grey matter looked normal, and there were no focal softenings The brainstem and cerebellum appeared normat with a normal-sized fourth ventricle. The inter. ventricular foramina, aqueduct, and lateral and median apertures were all fully patent.

\section{HISTOLOGY}

Sections from midbrain and upper pons showed features of an acute encephalitis with great pros liferation of microglial cells, necrosis of nerve cell and moderate lymphocytic cuffing of small vessess (fig 3). The lesions were roughly symmetrical and most intense in the substantia nigra. A large propo 2 tion of the pigmented cells in the substantia nigfers 


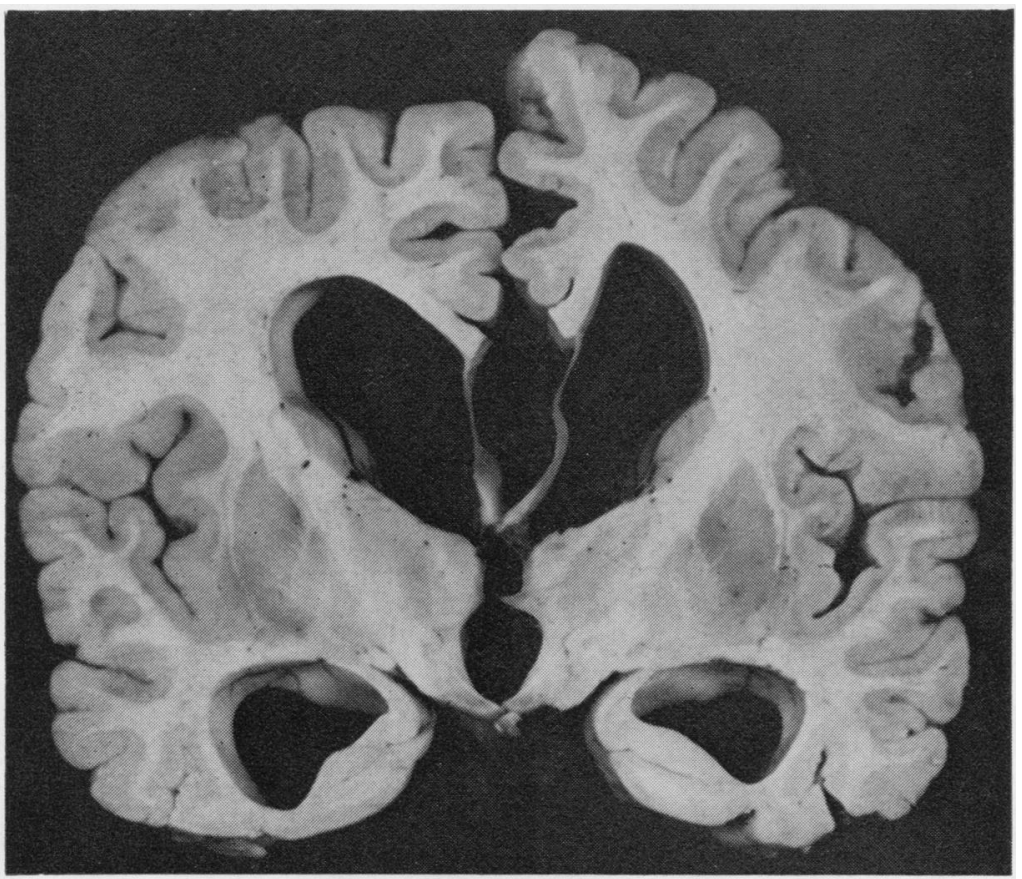

Fig 2 Coronal slice at anterior

thalamic level showing gross dilatation of lateral and third ventricles without convolutional flattening. (The corpus callosum was incised post mortem to aid fixation.)

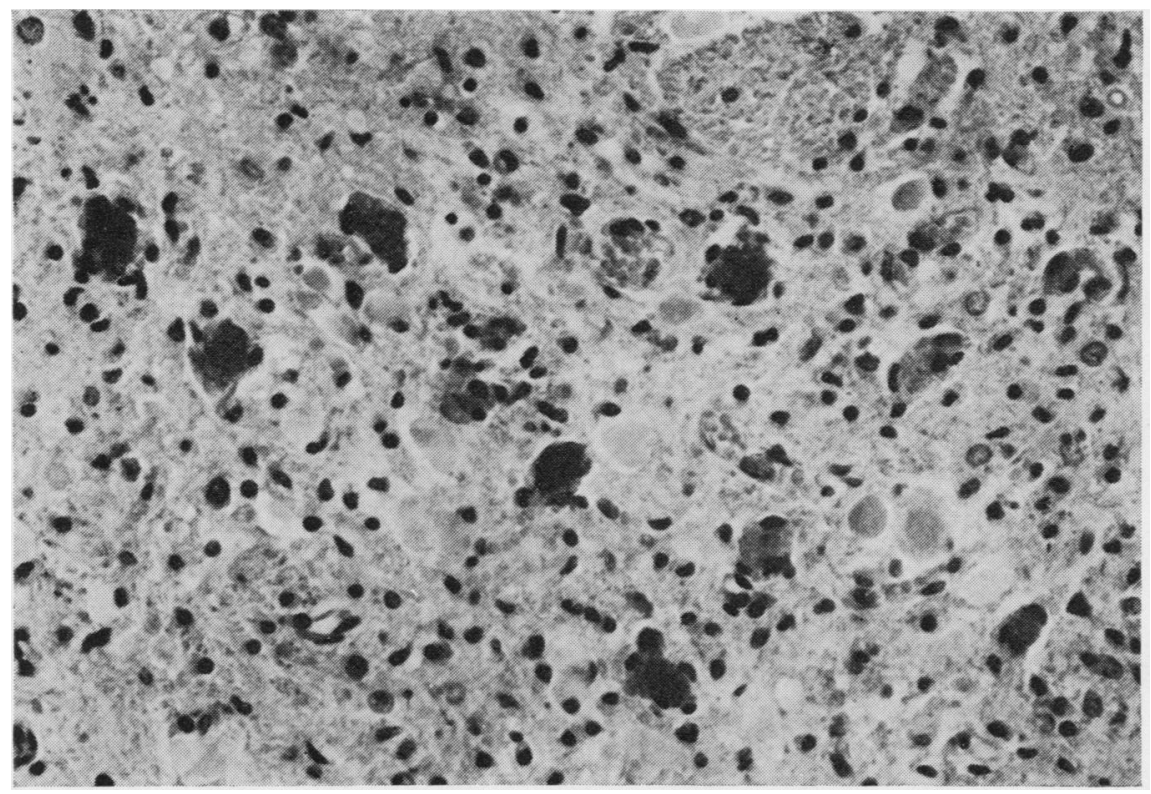

Fig 3 Substantia nigra showing necrosis of pigmented nerve cells and proliferation of microglia.

Haematoxylin and eosin $\times 285$. 
contained intranuclear eosinophilic inclusion bodies. These were often multiple and were sometimes accompanied by similar inclusions in the cytoplasm (figs 4 and 5). Intranuclear inclusions were also seen in small glial cells (fig 6). Small areas of microglial proliferation were present in other parts of the brainstem and in the thalamus, hypothalamus, and globus pallidus. Intranuclear inclusion bodies, without local inflammatory changes, were seen in the thalamus, globus pallidus, medial temporal cortex, and hippocampus and were very numerous in the visual cortex on the right side; a few were seen in Purkinje cells in the cerebellar cortex. No lesions of any kind were seen in samples of cerebral cortex and white matter from the convexities (including sites where tissue had been taken at necropsy for virological study) and there were no signs of perivenous myelin destruction. The leptomeninges appeared normal, and no leukaemic deposits were seen Nothing in the material suggested any form of congenital brain damage.

In summary, there was an acute encephalitis, with $\overrightarrow{\vec{s}}$ inclusion bodies, affecting mainly the midbrain and central cerebral structures. There was also a communicating hydrocephalus, probably of longer dura $\overline{\bar{n}}$ tion, the cause of which was not apparent; possibled causes include perinatal cerebral hypoxia.

\section{VIROLOGICAL EXAMINATION}

\section{Culture for viruses}

Cultures of a throat swab and a sample of CSF $10^{\circ}$ days before death and homogenates of tissue frome the frontal and parietal lobes, taken at necropsy, allo failed to yield any virus.

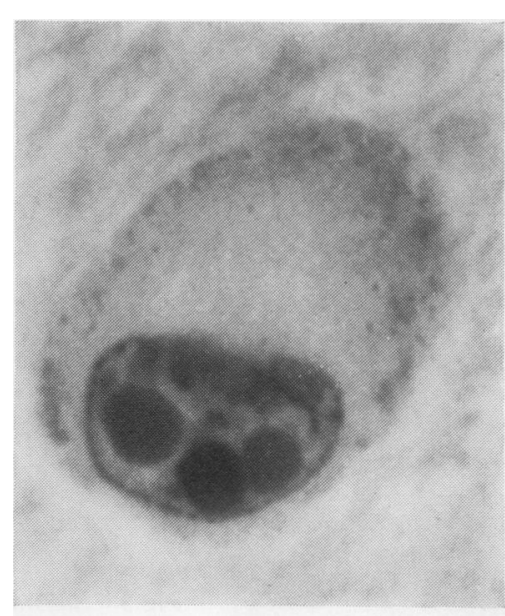

Fig $4 \mathrm{a}$

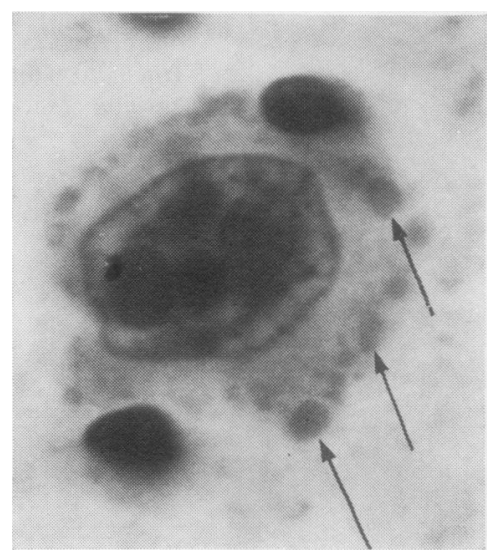

Fig 5
Fig 4 (a) and (b) Substantia nigra and intranuclear inclusions, single or multiple, in nerve cells. Haematoxylin and eosin $\times 1760$.

Fig 5 Substantia nigra: nerve cell with multiple intranuclear and intracytoplasmic (arrows) inclusions. Haematoxylin and eosin $\times 1760$. 


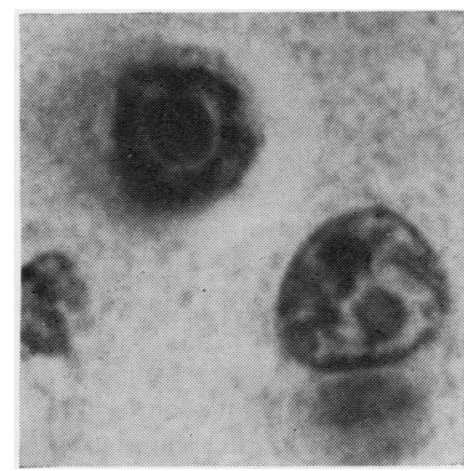

Fig 6 Intranuclear inclusions in glial cells. Haematoxylin and eosin $\times 1760$.

\section{Serology}

By the time inclusion bodies had been found in the brain, suggesting a viral encephalitis, serum was no longer available for antibody studies.

\section{Immunofluorescence}

Sections, $6 \mu \mathrm{m}$ thick, cut from paraffin-embedded tissue from the right temporal lobe of the brain, the visual cortex, the midbrain, and the lung were dewaxed, passed through alcohols to water, and washed for four hours in buffered saline. Sections were stained with a 1:20 dilution of human serum (measles CF titre 1:4000); a 1:10 dilution of guineapig serum (measles CF titre 1:1000) or a 1:20 dilution of rabbit serum (herpes simplex virus CF titre $1: 800$ ). Dilutions of human, guinea-pig, and rabbit sera without antibody were used for control staining. As a further check on the specificity of staining, sections were also treated with human anti-measles serum which had been absorbed with either normal Vero cells or Vero cells infected with the Edmonston strain of measles. This latter absorption removed specific antibody. After an hour's contact with the sera the sections were washed and treated with the appropriate fluorescein-conjugated anti-species globulin (Nordic Diagnostics) diluted 1:20 or 1:40. The sections, mounted in buffered glycerol, were examined under tungsten halogen illumination with an interference exciter filter.

Staining with human or guinea-pig serum containing measles antibody produced moderate numbers of fluorescent cells in the amygdaloid nucleus, the globus pallidus, and the substantia nigra. There was fluorescence of the cytoplasm of some neurons (fig 7) and of intranuclear inclusions in neurones and glial cells (fig 8). In the visual cortex there were numerous fluorescing inclusion bodies. Control sections stained with sera devoid of measles anti- body, or the serum absorbed with measles virus, did not show any fluorescent cells. The rabbit antiherpes serum did not give any fluorescence. Examination of the lung showed no evidence of measles or herpes antigen.

\section{Electron microscopy}

Only formalin-fixed tissue was available. Ultrathin sections were cut from tissues of five areas containing inclusion bodies, but electron microscopy revealed within the inclusions only filamentous material and no typical nucleocapsid tubules.

The identification of the agent in this child's brain was based solely on immunofluorescence using a technique for the identification of measles virus antigen in formalin-fixed tissue already employed by

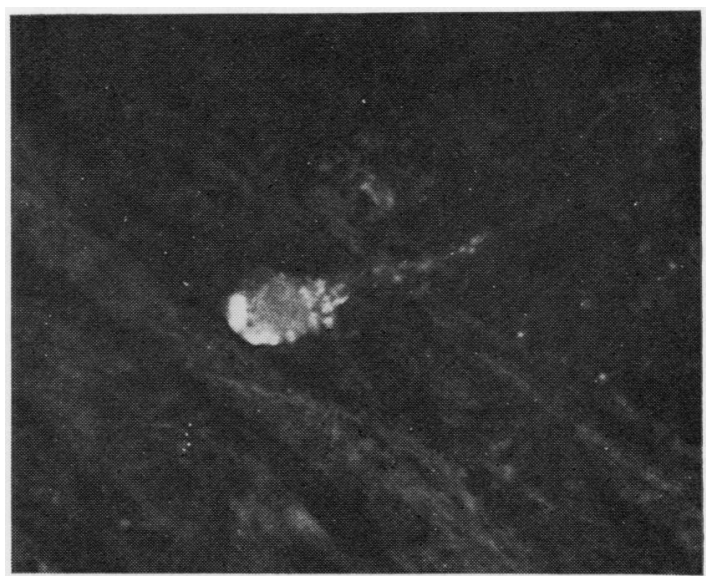

Fig 7 Amygdaloid nucleus: nerve cell showing fluorescence of cytoplasm and cytoplasmic inclusions. $\times 250$.

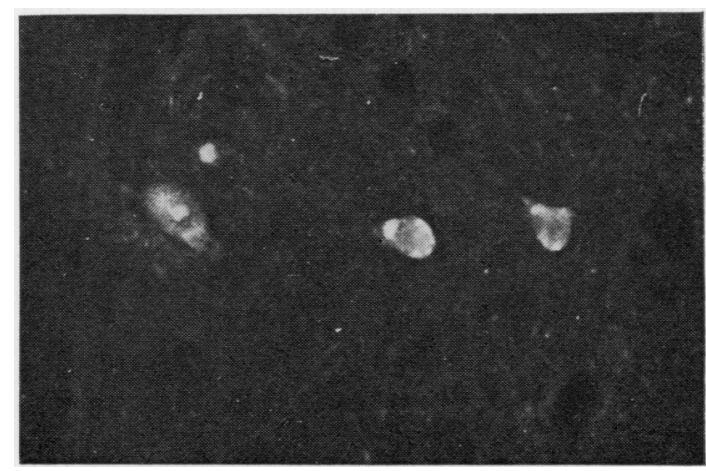

Fig 8 Substantia nigra: glial cells showing fluorescence of inclusion bodies. $\times 200$. 
Font et al (1973). The procedures used in the present case were checked by application to sections of formalin-fixed brain from three well-diagnosed cases of SSPE in which they produced characteristic fluorescence of antigen in glial cells and neurones. Because good fluorescence was observed with human and with guinea-pig antibody, and the staining by human antibody was abolished after absorption with measles-infected cells, there is no doubt that the cells in this brain contained antigen indistinguishable from that of measles virus.

\section{Discussion}

When a child in haematological remission presents with neurological disturbances, the possible causes include (1) recurrence of leukaemia in the brain, cord or meninges; (2) the damaging effects of chemotherapy and/or radiotherapy (Kay et al, 1972; Hendin et al, 1974; Rubinstein et al, 1975; Price and Jamieson, 1975; Weiss et al, 1974); (3) haemorrhages due to leukaemia or thrombocytopenia (Pitner and Johnson, 1973); and (4) infection to which these patients are abnormally susceptible (Levine $e t$ al, 1972; Simone et al, 1972). In the present case we found no signs of recurrent leukaemia, of radionecrosis, of toxic encephalopathy, or of intracranial haemorrhage, but there was clear evidence of an atypical infection of the brain.

Simone et al (1972) analysed the cause of death in 26 children with ALL, dying during a complete remission. In 24 of the 26 death was thought to be due to infection, 14 being viral infections, and five of these with evidence of encephalitis. More recently, Breitfeld et al (1973) reported two children with ALL in remission who contracted measles, followed after intervals of five and four months by a progressive disorder, fatal in two months or less. The first child had shown signs of encephalopathy with lethargy, weakness, hyporeflexia, fits, and coma. Necropsy showed giant-celled pneumonia, hepatitis, and nephritis, all attributable (on electron microscopic evidence) to measles. Inclusion bodies containing typical microtubules were present in neurons and glial cells. Measles antibody titre (complement fixation) was $1: 8$. In the second child there was a very similar encephalopathy; inclusion bodies, with microtubules, were present in all parts of the brain and there was cuffing of vessels by lymphocytes and plasma cells. The measles antibody titre was 1:512. There was no sign of recurrent leukaemia in either case. Sluga et al (1975) described a similar case, developing measles during remission and two months later a progressive encephalopathy, fatal in two weeks. This was attributed to cerebral leukaemia and was treated by irradiation. At necropsy no leukaemic deposits were found, but there was a giant-celled pneumonia, and abundant inclusion bodies were seen in cerebral neurons and neuroglia.

Mitus et al (1959) noted poor immune response in four treated leukaemic children who developed af giant-cell pneumonitis (fatal in two cases) following a typical measles rash, and observed an abnorma persistence of the virus in the nasopharynx for three to four weeks after the rash. There are also reports (for example, Meadow et al, 1969; Lyon, 1972) of s measles infections taking an atypical and deadly $\vec{O}$ course in patients who have undergone immuno- $\overrightarrow{-}$ suppression for diseases other than leukaemia.

Measles is known to affect the nervous system in several different ways. The first is so-called 'measles? encephalitis', an acute feverish illness with onset: usually about five days after the rash. In non-fatal $\overrightarrow{0}$ cases the disease does not progress and does noto recur (Miller et al, 1956; Scott, 1967). The lesions in cases of this type are those of a perivenous en-음 cephalomyelitis (PVEM). They are widely dis- tributed, principally in white matter, and consist in long perivenous sleeves of myelin destruction with음 spreading inflammatory infiltration around the affected vessels. Nerve cells are not directly affected. $\overrightarrow{0}$ The histological picture is indistinguishable from that seen in encephalitis following vaccinia and othor. virus infections. It is also the picture seen in theo experimental 'allergic' encephalitis produced injection of brain tissue or of an extract of myelin proteins. Because of this histological similarity, and because of repeated failures to isolate virus from $\stackrel{\mathbb{Q}}{2}$ affected brains, it is generally thought that acute $\vec{\circ}$ measles encephalitis is an auto-immune, cell- 3 mediated disorder and not the direct effect of measles virus in the brain.

A second complication of measles and of other viral infections, seen mainly in infants and young children, is an acute, often fatal, encephalopathy 3. with onset a few days after the primary disease. The brain is diffusely swollen and there are widespread $\frac{\mathrm{O}}{3}$ hypoxic (or hypoglycaemic) changes in nerve cells, but there is no perivenous myelin destruction or? inflammatory infiltration. The liver is commonly $\frac{7}{0}$ found to be enlarged and fatty (the term 'Reye's syndrome' is applied to such cases) and there is often of a profound hypoglycaemia attributable to liver $N$ failure. An acute 'toxic' encephalopathy of this type (rather than PVEM) is the usual cerebral complica- $\omega$ tion of measles and other infections in infants (Miller et al, 1956; Scott, 1967; Hammon and Ho, $\stackrel{O}{\circ}$ 1973). The role of the virus in this condition, as in post-measles PVEM, remains obscure (Linnemann ${ }^{+}$ et al, 1975). There have been no reports of virus $\frac{0}{0}$ isolation from affected brains.

The third cerebral complication of measles is $\frac{\stackrel{?}{\mathbb{Q}}}{\mathbb{Q}}$ 
subacute sclerosing panencephalitis (SSPE). The onset of this condition, often several years after a commonplace attack of measles, is insidious with progressive lethargy and mental deterioration leading to profound dementia and other signs of widespread cerebral damage. Myoclonic jerking is a characteristic feature of the condition, epileptic seizures much less so. The disease is almost confined to the first two decades of life and usually leads to death in less than 12 months. The lesions, which vary in relative intensity from case to case, consist in $(a)$ focal inflammatory changes with proliferation of microglia and lymphocytic cuffing of vessels, affecting both grey matter and white; (b) astrocytic hyperplasia, most marked in the cerebral white matter, leading to a dense fibrillar gliosis; $(c)$ the presence of intranuclear (less frequently intracytoplasmic) inclusion bodies in neurones and neuroglial cells. Perivenous myelin destruction is not a feature of this condition. The evidence relating measles virus to SSPE is reviewed by ter Meulen et al (1972).

In the present case, PVEM and acute "toxic" encephalopathy are ruled out by the time course, the clinical picture, and the pathological findings. Histologically, it resembles SSPE in the matter of inclusion bodies but differs in the fact that the white matter, and most of the cortex, appear intact, the major lesions being found in the midbrain, basal ganglia, medial temporal, and occipital cortex. Both clinically and pathologically it closely resembles the cases of Breitfeld et al (1973) and of Sluga et al (1975). Breitfeld et al firmly diagnosed SSPE in their cases; they admit that the time course was unusually rapid but attribute this acceleration to the effects of leukaemia, or of treatment, or both. While we agree that the disease in such cases resembles SSPE, we feel that it is improper to apply that name because the disease was not subacute but acute; it was not panencephalitis because the white matter was unaffected and there was no sclerosis. The term 'measles inclusion-body encephalitis', though cumbersome, is more appropriate for what appears to be a new manifestation of measles infection peculiar to immunosuppressed patients.

As to the general problem of diagnosis in cases of cerebral disorder during a remission in ALL, there is no simple procedure for distinguishing between meningeal leukaemia, the effects of therapy, haemorrhage, and infection. The symptoms and neurological signs of all four are variable and overlapping.

As antileukaemic therapy prolongs the life of patients more atypical virus infections will occur, and in any episode of cerebral disorder virological as well as haematological tests should be done, though in some cases the diagnosis may be revealed only by a comprehensive postmortem examination.
Our thanks are due to Wing Commander G. C. Turner, consultant in medicine, and to Squadron Leader N. G. Flanagan, consultant in pathology, for referring this case: to Dr A. C. Buck for the virological culture; and to Dr J. T. Hughes for the electron microscopy.

\section{References}

Breitfeld, V., Hashida, Y., Sherman, F. E., Odagiri, K., and Yunis, E. J. (1973). Fatal measles infection in children with leukemia. Lab. Invest., 28, 279-291.

Font, R. L., Jenis, E. H., and Tuck, K. D. (1973). Measles maculopathy associated with subacute sclerosing panencephalitis. Arch. Path., 96, 168-174.

Hammon, W. McD., and Ho, M. (1973). Viral encephalitis. $D M$, February 1973, 1-47.

Hendin, B., de Vivo, D. C., Torack, R., Lell, M. E., Ragab, A. H., and Vietti, T. J. (1974). Parenchymatous degeneration of the central nervous system in childhood leukemia. Cancer (Philad.), 33, 468-482.

Kay, H. E. M., Knapton, P. J., O’Sullivan, J. P., Wells, D. G., Harris, R. F., Innes, E. M., Stuart, J., Schwartz, F. C. M., and Thompson, E. N. (1972). Encephalopathy in acute leukaemia associated with methotrexate therapy. Arch. Dis. Childh., 47, 344-354.

Levine, A. S., Graw, R. G., Jr., and Young, R. C. (1972). Management of infections in patients with leukemia and lymphoma: current concepts and experimental approaches. Semin. Haematol., 9, 141-179.

Linnemann, C. C., Jr., Shea, L., Partin, J. C., Schubert, W. K., and Schiff, G. M. (1975). Reye's syndrome: epidemiologic and viral studies, 1963-1974. Amer. J. Epidem., 101, 517-526.

Lyon, G. (1972). Action des immuno-suppresseurs sur une encéphalite virale (rougeole): inhibition de la réaction inflammatoire. C.R. Acad. Sci. (Paris), [D] 274, 1878-1879.

Meadow, S. R., Weller, R. O., and Archibald, R. W. R. (1969). Fatal systemic measles in a child receiving cyclophosphamide for nephrotic syndrome. Lancet, 2, 876-878.

ter Meulen, V., Katz, M., and Müller, D. (1972). Subacute sclerosing panencephalitis: a review. Curr. top. Microbiol. Immunol., 57, 1-38.

Miller, H. G., Stanton, J. B., and Gibbons, J. L. (1956). Para-infectious encephalomyelitis and related syndromes. Quart. J. Med., 25, 427-505.

Mitus, A., Enders, J. F., Craig, J. M., and Holloway, A. (1959). Persistence of measles virus and depression of antibody formation in patients with giant-cell pneumonia after measles. New Engl. J. Med., 261, 882-889.

Pitner, S. E., and Johnson, W. W. (1973). Chronic subdural hematoma in childhood acute leukemia. Cancer (Philad.) 32, 185-190.

Price, R. A., and Jamieson, P. A. (1975). The central nervous system in childhood leukaemia. II. Subacute leukoencephalopathy. Cancer (Philad.), 35, 306-318.

Rubinstein, L. J., Herman, M. M., Long, T. F., and Wilbur, J. R. (1975). Disseminated necrotizing leukoencephalopathy: a complication of treated central nervous system leukemia and lymphoma. Cancer (Philad.), 35, 291-305.

Scott, T. F. McN. (1967). Postinfectious and vaccinal encephalitis. Med. Clin. N. Amer., 51, 701-727.

Simone, J. V., Holland, E., and Johnson, W. (1972). Fatalities during remission of childhood leukaemia. Blood, 39, 759-770.

Sluga, E., Budka, H., Jellinger, K., and Pichler, E. (1975). SSPE-like inclusion body disorder in treated childhood, leukemia. Acta Neuropath. (Berl.) Suppl., 6, 267-272. 
Weiss, H. D., Walker, M. D., and Wiernik, P. H. (1974). Neurotoxicity of commonly used antineoplastic agents. New Engl. J. Med., 291, 75-81 and 127-133.

\section{Addendum}

Since the above was written there has been a report of a child, aged 2 years, with ALL in remission who suffered from convulsions for three weeks and diect in status epilepticus (Report to the MRC of the Working Party on Leukaemia in Childhood, Brit med. J., 6 September 1975, pages 563-566). Sections of the brain of that child submitted to us for immunoe fluorescence study showed cells containing measleso antigen. 